Article

\title{
Risk of Children's Dermal Exposure to Galaxolide through Personal Care Products
}

\section{Patrícia Correia ${ }^{1,2}$, Agostinho Cruz ${ }^{1}$, Lúcia Santos ${ }^{2}$ and Arminda Alves ${ }^{2, *}$}

1 Núcleo de Investigação em Farmácia, Centro de Investigação em Saúde e Ambiente (CISA), Escola Superior de Tecnologia da Saúde do Porto/Instituto Politécnico do Porto (ESTSP/IPP), Rua Valente Perfeito, 322, 4400-330 Vila Nova de Gaia, Portugal;

E-Mails: pcc@estsp.ipp.pt (P.C.); asc@estsp.ipp.pt (A.C.)

2 LEPABE - Laboratory for Process Engineering, Environment, Biotechnology and Energy, Faculty of Engineering, University of Porto, Rua Dr. Roberto Frias, 4200-465 Porto, Portugal; E-Mail: 1santos@fe.up.pt

* Author to whom correspondence should be addressed; E-Mail: aalves@fe.up.pt; Tel.: +351-22-508-1652 (ext. 1883).

Academic Editor: Enzo Berardesca

Received: 1 March 2015 / Accepted: 14 April 2015 / Published: 21 April 2015

\begin{abstract}
Galaxolide is the most used fragrance since the early 1990s, and it has been largely detected in environmental and biological matrices. This polycyclic musk is present in almost all of our daily products, so the risk of human exposure is substantial, as it had been proved by its detection in human tissues and fluids. Due to the lack of information about the concentrations found in consumer products, monitoring data is needed for exposure assessment purposes. Dermal contact, mostly by personal care products, seems to be the major route of human exposure to galaxolide, and, due to the immaturity of young children's skin, exposure consequences can be worse in this population. The main objective of this study was to evaluate galaxolide levels in personal care products used by children of Oporto (Portugal), aged 0-5 years, and relate it with consumer habits. Consumer patterns were obtained through 250 questionnaires to caregivers of Oporto children. The 79 most used products were extracted by a dispersive solid phase extraction methodology known as QuEChERS and galaxolide was determined by High Performance Liquid Chromatography (HPLC) with fluorescence detection. The concentrations ranged between $0.001 \pm 0.001 \mathrm{mg} \cdot \mathrm{kg}^{-1}$, on a baby wipe, and $300.480 \pm 8.819 \mathrm{mg} \cdot \mathrm{kg}^{-1}$, on glycerin soap, which may correspond to an estimated daily dermal exposure of $277.10 \pm 0.02 \mu \mathrm{g} \cdot \mathrm{day}^{-1}$
\end{abstract}


on the population of Oporto children. This value is in the range of the results observed for adults, although no information of toxicological risk for children is available.

Keywords: galaxolide; dermal exposure risk; children; personal care products; QuEChERS; HPLC-fluorescence

\section{Introduction}

Musks are synthetic fragrances widely used in innumerous daily products, like personal care products (PCP), in order to maintain the desired scent. They are applied as fixatives, because of their low volatility against other fragrances, retarding their release. There are four main groups of musks, according to their physical-chemical properties: nitro musks (NM), polycyclic musks (PM), macrocyclic musks (MM), and alicyclic musks (AM) [1].

The PM galaxolide (HHCB; 1,3,4,6,7-hexahydro-4,6,6,7,8-hexamethylcyclopenta- $\gamma$-2-benzopyran; Figure 1) is the most used musk in the world since the early 1990s [2].

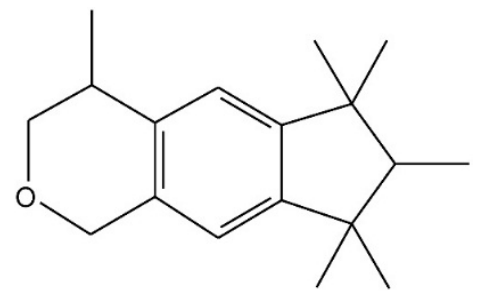

Figure 1. Galaxolide (HHCB) chemical structure.

Due to the massive use of fragranced PCPs that are frequently water rinsed after application, it is expected that $77 \%$ of musks are discharged into the sewer system [3]. As HHCB has a high octanol-water partition coefficient $\left(\log K_{\mathrm{ow}}=5.9\right)$ and relatively low water solubility $\left(1.75 \mathrm{mg} \cdot \mathrm{L}^{-1}\right)$, this compound has been found in wastewater treatment plants (influents, effluents, and in sewage sludge) and even in environmental matrices (surface water, sediments, and suspended matter) [2]. HHCB also reaches the biological food chain, and has been detected in several biological matrices, most of them aquatic fauna [2,3]. Therefore, the risk of exposure to HHCB by humans is significant, not only directly by PCPs and other products (dermal, oral, and inhalation exposure), but also by food and the environment. In fact, HHCB has already been found in human tissues and fluids like blood, human fat, and breast milk $[2,3]$.

The main source of human exposure to musks is expected to be by the dermal application of PCPs, especially by leave-on products [3]. Musks have been described as potentially endocrine disrupters, although low estrogenic effects have been reported for HHCB in humans at current levels of exposure [4]. It has also been reported that perfumes that contain several fragrances, like HHCB, may play an important role in inducing genetic mutations that can lead to autism spectrum disorders, and the incidence of this disorder has increased in children since the early 1990s [4]. Nevertheless, the providing the details of the entire fragrance composition is not legally mandatory in European Union, forcing companies to only to refer to "Parfum" or "Aroma" in the product composition [5]. 
There are more than 2000 known fragrances used in PCPs like perfumes, moisturizers, bath or hair care products, or even cosmetic products [6]. But there are also some PCPs with such a residual quantity of fragrances that are not referenced in the product's composition, and can even be labelled as "fragrance-free", namely some children or baby PCPs.

Children's skin is different from adults' skin, because after birth, and during the first months or years of life, the cutaneous structure and functions are in adaptation and maturation [7,8]. At this age, the skin barrier, that prevents the loss of water and the penetration of irritants or allergens, is less developed than in adults [9], mainly due to the lack of some lipids, higher levels of water and $\mathrm{pH}[10,11]$. Additionally, the cutaneous permeability can be altered, for example, by the use of soaps and detergents that can raise skin $\mathrm{pH}$, especially in newborn babies [9]. So, the use of PCPs in children can damage the skin barrier, allowing allergens to enter through the skin [9-11]. Consequently, depending on some predisposing factors and also on the presence of certain PCP ingredients, such as fragrances, children's skin is more vulnerable to adverse reactions like atopic eczema, chemical dermal allergies and hypersensitivity [7-9], or even absorption into the bloodstream. A study in the elderly population, which also have the epidermal barrier altered, showed higher systemic absorption of musks than in healthy adults [12], but no studies were found in children. So, children's dermal exposure risk to HHCB may be higher than in adults and no data is available regarding the use of PCPs by this population. The maturation process of skin may be beyond the first year of life [10], and this should be taken into account when choosing the population under scrutiny.

Few reports refer to the detection of HHCB in PCPs themselves, even in the ones targeting adults. The reported HHCB concentrations ranged from below 0.003 to $22,000 \mathrm{mg} \cdot \mathrm{kg}^{-1}$ [3,13-18], and only two of the seven studies are European $[13,15]$. Patterns of fragrance consumption may differ around the world, and it is mentioned that North European countries consume less fragranced products than the southern ones [2]. Only a previous study of this work team was performed in this latter region, namely in Portugal [15], and there is not available data about the PCP consumption patterns, mostly only the risk of dermal exposure to musks by European children.

The main purpose of this work was to estimate the risk of children's dermal exposure to galaxolide in Oporto (Portugal). Because of the referred lack of information on the PCP consumer habits and PCPs' fragrance compositions, this particular study intends: (i) to find the most used PCPs among Oporto children, concerning moisturizers, toothpastes, bath products, diaper change products, and sunscreens; (ii) to quantify the HHCB concentration in each of those PCPs; (iii) to estimate the mean daily frequency, quantities, and site of application of each type of PCP in Oporto children, and (iv) to evaluate the risk of dermal exposure to HHCB in children.

\section{Experimental Section}

\subsection{Questionnaire}

A questionnaire regarding consumer habits (Supplementary File-Questionnaire), previously validated with a 50-individual sample, was applied to child caregivers (mothers and fathers) that filled out a questionnaire for each child. The inclusion criteria were children aged between 0 and 5 years, and resident in the district of Oporto. Based on these inclusion criteria and on the final results of the 
Portugal Census 2011 [19], the population size was estimated to be 85,019 , which corresponds to $30 \%$ of the population of up to 14 years of age living in the district of Oporto. Thus, with a margin of error of $5 \%$ and a confidence level of $90 \%$, a sampling size of 270 children was estimated to guarantee representativeness of the study. Over 300 questionnaires were delivered on paper from January to March 2013 (three months). The questionnaire had a cover page with a brief description of the purpose of the study and the possibility of respondents to provide their consent before answering (Supplementary File-Questionnaire). Respondents returned the completed questionnaires with no personal identification, and a number was attributed to each one, ensuring anonymity. The questionnaire was analyzed in terms of social-demographic characteristics and consumer habits, namely most used PCPs (brands and types), as well frequency and quantity of application. The PCPs were selected from the questionnaires results and complemented with two hypermarkets statistics of sales.

Besides this information, six of the 250 caregivers agreed to respond to an annex of the questionnaire (Supplementary File-Questionnaire) where the used amounts were precisely quantified. These responses correspond to the utilization of PCPs by six children aged between 9 and 59 months, where half of them were from each gender. For each used PCP, the initial weight of the package was recorded as well as the daily frequency of use over seven days, after which the package was weighed again. Thus, it was possible to obtain used average quantities for each type of PCP (body moisturizer, face moisturizer, toothpaste, bath gel, soap, shampoo, hair conditioner, baby wipes, diaper change cream, and sunscreen). Statistical analysis was performed using Microsoft Excel $2007^{\circledR}$.

\subsection{Chemicals and Samples}

Based on consumer habits, 79 PCPs were selected as the most used by this population (62 PCPs based on the questionnaire results and 17 PCPs from market data obtained from two of the greatest hypermarkets chains in the region). These selected PCPs were purchased in pharmacies and hypermarkets and the final sample was composed of: twenty one moisturizers, seven toothpastes, nine shampoos, thirteen " 2 in 1 " bath products, two soaps, one cleansing solution, four hair conditioners, six baby wipes, eight barrier creams, and eight sunscreens.

A commercial HHCB standard with a 50\% purity in diethyl phthalate (DEP) was purchased from SAFC (St. Louis, MO, USA). A working standard solution of $\mathrm{HHCB}$ at $60 \mathrm{mg} \cdot \mathrm{L}^{-1}$ was prepared in absolute ethanol (pro-analysis grade, from Riedel-de Haën, Honeywell Specialty Chemicals Seelze $\mathrm{GmbH}$, Hanover, Germany) for calibration purposes. Stock solutions of HHCB at concentrations varying from 455 to $600 \mathrm{mg} \cdot \mathrm{L}^{-1}$ in acetonitrile (HPLC isocratic grade, from VWR International, Radnor, PA, USA) and stored in the dark at $-4{ }^{\circ} \mathrm{C}$, were used for the spiking of samples for recovery studies.

The HPLC mobile phase was prepared with deionized water and acetonitrile, acidified with glacial acetic acid (100\%), and the extraction solvent and sorbents were also the same as described in previous work by this team [15].

\subsection{Extraction and Analytical Method}

The referenced PCPs were extracted by dispersive solid phase extraction, commonly named as QuEChERS, and HHCB concentration was determined by High Performance Liquid Chromatography with fluorescence detection (HPLC-FL), as described before [15]. At least duplicates of all samples were 
extracted and analyzed. Briefly, $2 \mathrm{~g}$ of samples were rigorously weighed and vigorously shaken for 3 min with $5 \mathrm{~mL}$ of water (co-solvent). Then, $15 \mathrm{~mL}$ of acetonitrile (solvent) was added, shaken for another $3 \mathrm{~min}$, and homogenized in an ultrasonic bath for $10 \mathrm{~min}$. The two sequential steps of extraction and cleanup were performed subsequently adding the corresponding QuEChERS sorbents and mixing, as described elsewhere [15]. To enable total phase separation, centrifugation was performed at $3700 \mathrm{rpm}$ for $10 \mathrm{~min}$ at the end of each of these two steps. The supernatant was collected in a $50 \mathrm{~mL}$ PP tube and stored in a freezer $\left(-18{ }^{\circ} \mathrm{C}\right)$ until HPLC-FL analysis. Validation parameters of this method were already reported in the previously mentioned study [15] and include: a linearity range of $0.005-1.002 \mathrm{mg} \cdot \mathrm{kg}^{-1}$, a limit of detection (LOD) of $0.001 \mathrm{mg} \cdot \mathrm{kg}^{-1}$, a repeatability below $11.3 \%$, an intermediate precision of $2.5 \%$ and a global uncertainty below $4 \%$ for concentrations under $0.2 \mathrm{mg} \cdot \mathrm{kg}^{-1}$. Accuracy was specifically evaluated by the recovery percentage for each type of PCP fortified with HHCB spikes (see Section 3.2).

\subsection{Blank Issues/Quality Assurance}

The analyst avoided wearing scented personal products whenever assays were performed. Additionally, for each analyzed product, a fresh pair of disposable gloves were used to prevent HHCB cross contamination. Glassware was washed using non fragranced detergent and all the materials and reagents were tested to be free of interferences, by performing extraction blank assays, as no HHCB was detected (below LOD as referred in Section 2.3) as described before [15].

\section{Results and Discussion}

\subsection{Questionnaire}

The aim of this study was to collect information to assess the risk of dermal exposure of children to the synthetic fragrance galaxolide contained in toiletries and personal care products. In order to create this data pool, a questionnaire for each child was given to caregivers of children aged between 0 and 5 years, all residents in the Oporto district (inclusion criteria). With these inclusion criteria, the final sample size was set at 250 children, corresponding to a representative sample population for a $5.2 \%$ margin of error and a $90 \%$ confidence level.

\subsubsection{Social-Demographic Characterization of Children and Families}

\section{Children Characterization}

Children's ages were selected assuming a previous reported range [9]. The children were divided into six age categories corresponding to each year of life, except for the first year, where the range was two half years. This was done because, during the first year, children experience exponential growth and major modifications on their skin structure, mainly during the first half year [7,9]. They were aged 0-5 months (8.3\%), 6-11 months (9.1\%), 12-23 months (19.0\%), 24-35 months (21.3\%), 36-47 months (26.1\%), and 48-59 months (16.2\%). The distribution of the six age groups by gender is shown in Figure 2, where 51\% belongs to the female and $47 \%$ to the male gender. This distribution is according to Portugal Census 2011 [19] for the Oporto district: 52\% female and 48\% male. 


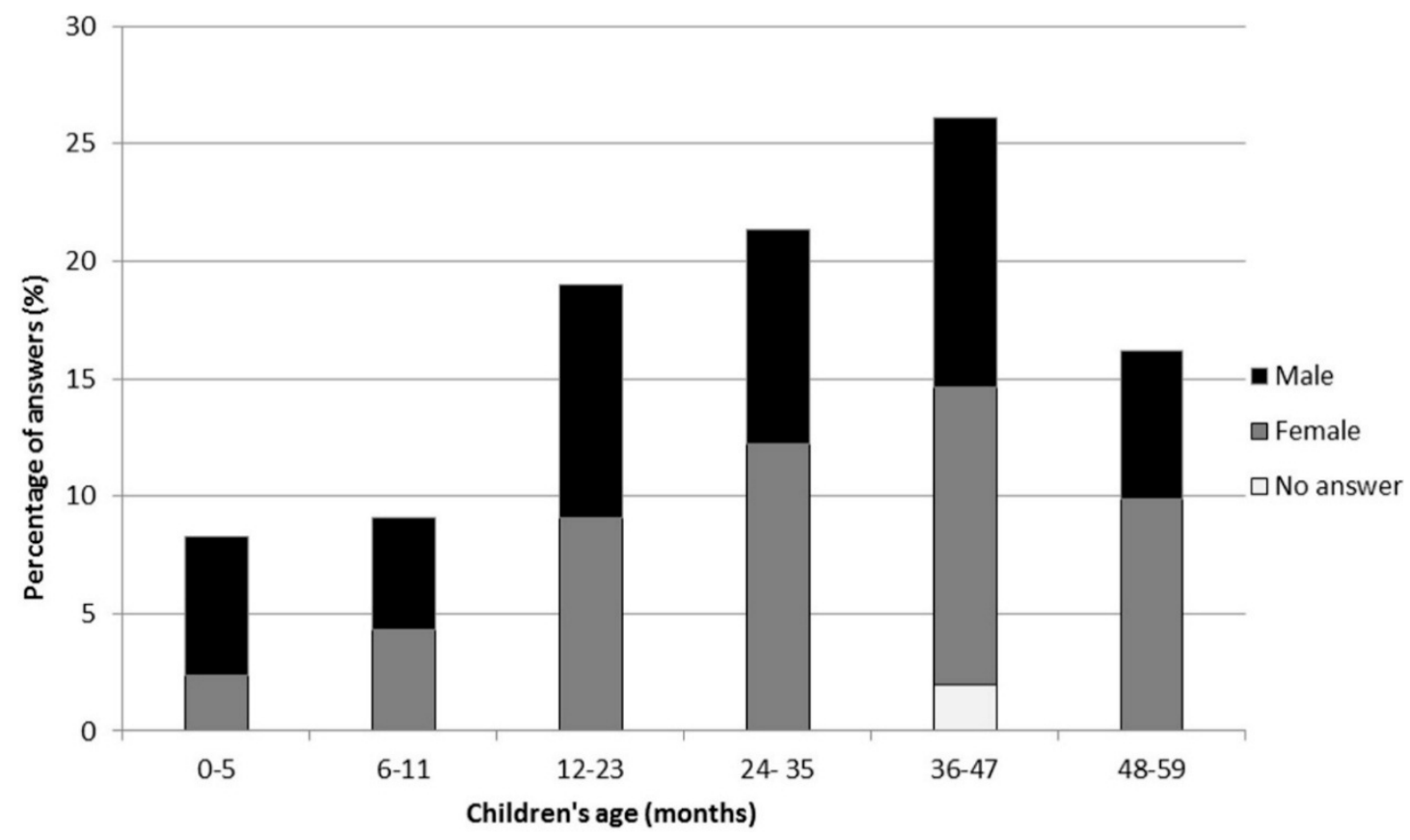

Figure 2. Distribution of inquired children by age and gender (total 253 responses).

The residence area of the inquired children included all 18 municipalities of the Oporto district with a distribution that mainly comprises the main city of Porto $(26.8 \%)$ and also other municipalities like Gaia (16.8\%), Amarante (15.2\%), Matosinhos (10.4\%), and Maia (8.8\%). This distribution is slightly different from the real distribution based on the final results for the northern region of the Portugal Census 2011 [19], especially for the municipalities of Amarante and Gondomar.

Caregivers and Families' Characterizations

Most questionnaires (89.2\%) were answered by the children's mothers, $8.8 \%$ by the fathers, and $2.0 \%$ did not answer to this question. The caregivers, with an average of $34.7 \pm 4.3$ years, are mostly in charge with only one child under five years old (79.2\%) and have an undergraduate degree (38.0\%) or a Master's degree (18.8\%), and few (4.0\%) have less than six years of schooling (Figure 3 ).

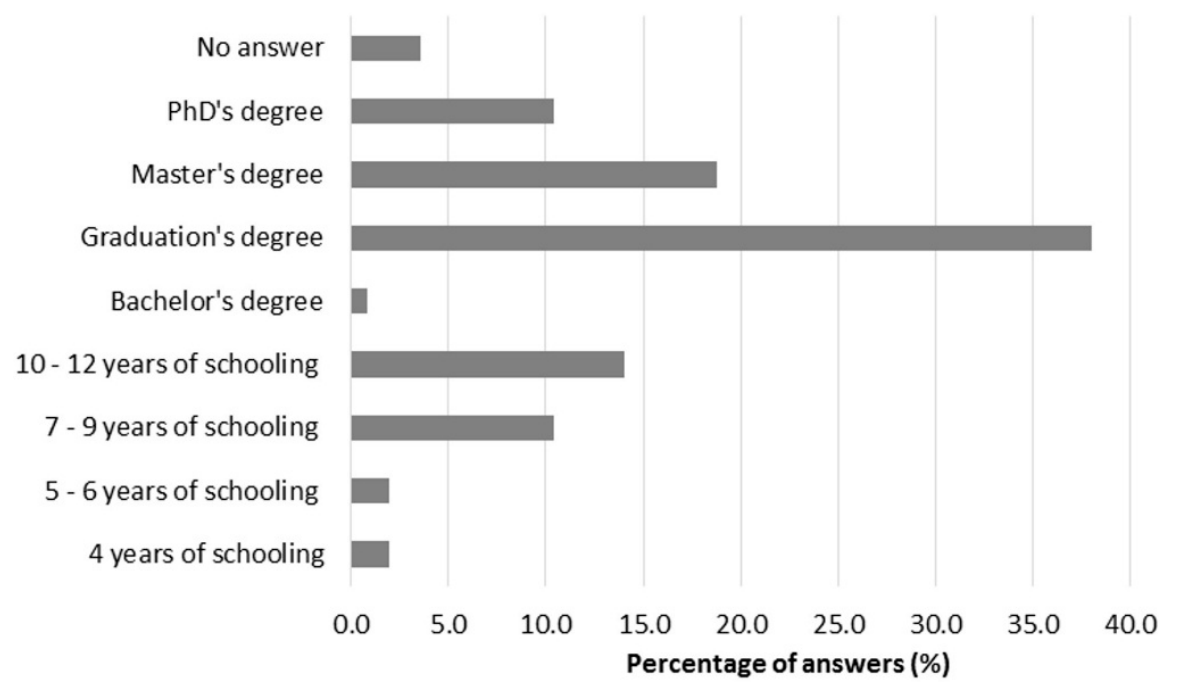

Figure 3. Qualifications of caregivers. 
In terms of professional occupation, $20.4 \%$ of caregivers work both in the area of "Education" as in "Health and social work", $16.4 \%$ in "Other service activities", and $8.8 \%$ in the "Industry", but 5.2\% are "Unemployed" (Figure 4). Families are mainly comprised of three (45.0\%) or four members $(44.0 \%)$ and most of them $(53.6 \%)$ reported a monthly income equal or superior to three minimum wages, while for $6.4 \%$, monthly income was equal to the minimum wage (about 466 euros/month at the time of the study). Nevertheless, $9.2 \%$ of the respondents have chosen not to answer to this question.

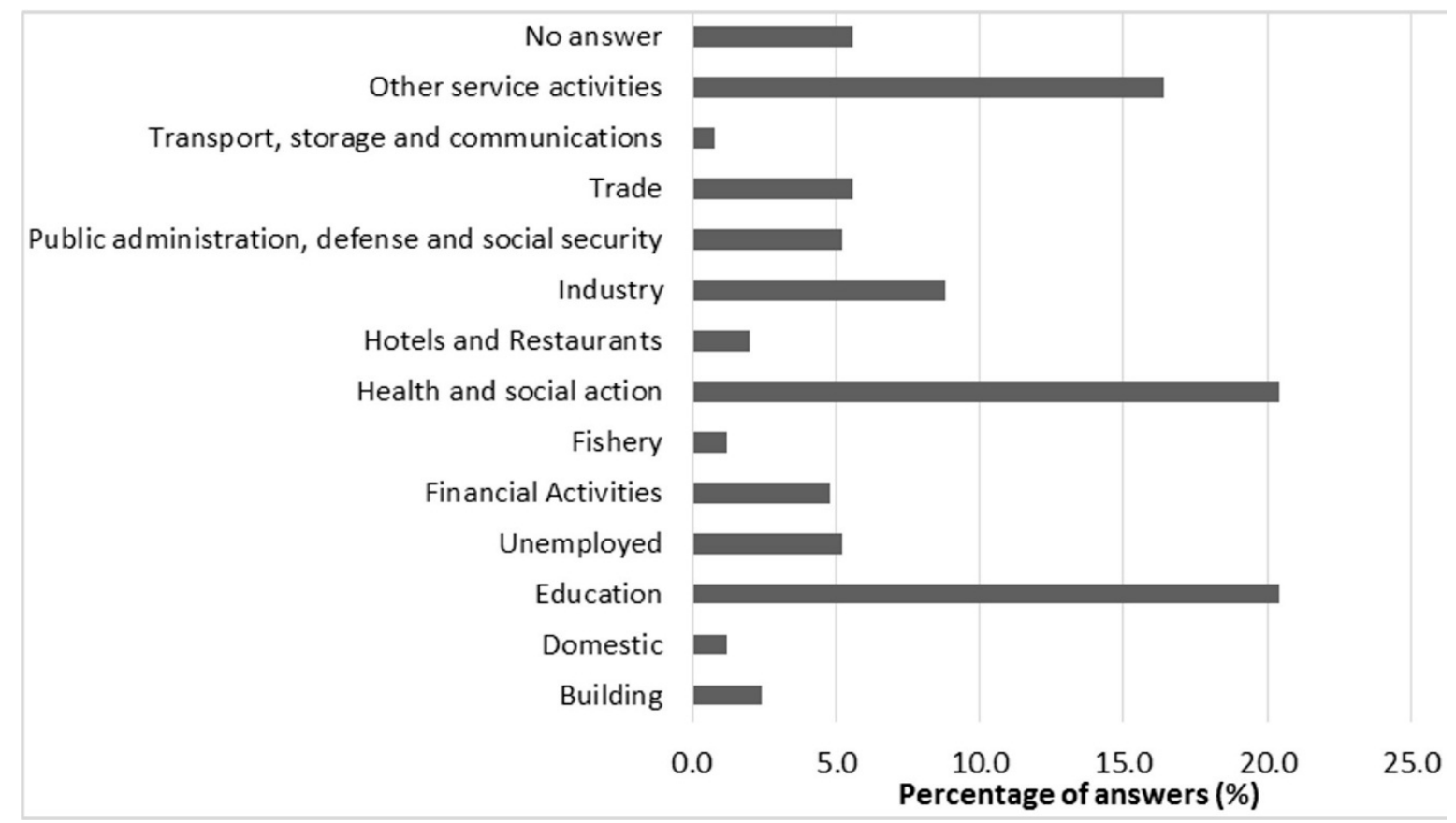

Figure 4. Caregivers' professional occupations.

This section of the questionnaire, corresponding to the characterization of the caregivers and the families, was not mandatory, but only a minor fraction of respondents $(2.4 \%)$ did not answer all of these questions.

\subsubsection{Consumer Habits}

The frequency and the mode of application (applied amount and site of application) of the PCPs used in children are described in Table 1. Notice that, regarding the mode of application, qualitative answers such as "a walnut of product" were inserted in order to facilitate the answers.

Moisturizing products are applied mostly once $(52.8 \%)$ or twice $(20.8 \%)$ a day on the face $(92.8 \%)$, trunk $(82.8 \%)$ and members $(82.4 \%)$ as a thick layer $(80.8 \%)$. Another study about PCP use in children in the United States of America (USA), made between 2010 and 2011, reported a similar frequency of 1.3 times a day for hydration [20].

Oral hygiene is performed one $(24.0 \%)$ or two (46.4\%) times a day, applying toothpaste on teeth and tongue (52.8\%). The used amount of this kind of product corresponds mainly to the nail size of the little finger of the child (60.0\%). Children who do not use toothpaste (16.4\%) are mostly children under 12 months (15.6\%), which is understandable, as most children at this age do not yet have dentition. 
Table 1. Frequency of utilization, applied amount and site of application of personal care products (PCPs) by the inquired children (percentage of answers below).

\begin{tabular}{|c|c|c|c|c|c|c|c|c|}
\hline Parameters & Moisturizer & Toothpaste & $\begin{array}{c}\text { Bath } \\
\text { Gel/Soap }\end{array}$ & Shampoo & $\begin{array}{c}\text { Hair } \\
\text { Conditioner }\end{array}$ & $\begin{array}{l}\text { Diaper } \\
\text { Change } \\
\text { Hygiene }\end{array}$ & $\begin{array}{l}\text { Diaper } \\
\text { Change } \\
\text { Cream } \\
\end{array}$ & Sunscreen \\
\hline $\begin{array}{c}\text { Frequency } \\
\text { of utilization }\end{array}$ & $\begin{array}{c}\text { Once a day } \\
(53 \%)\end{array}$ & $\begin{array}{c}\text { Two times a } \\
\text { day }(46 \%)\end{array}$ & $\begin{array}{c}\text { Once a day } \\
(68 \%)\end{array}$ & $\begin{array}{c}\text { Once a day } \\
(41 \%)\end{array}$ & $\begin{array}{c}\text { Once a day } \\
(10 \%)\end{array}$ & $\begin{array}{l}\text { Five times } \\
\text { a day } \\
\text { (mean) }\end{array}$ & $\begin{array}{c}\text { Five times } \\
\text { a day } \\
\text { (mean) }\end{array}$ & $\begin{array}{c}\text { Three times } \\
\text { a day * } \\
\text { (mean) }\end{array}$ \\
\hline $\begin{array}{l}\text { Applied } \\
\text { amount }\end{array}$ & $\begin{array}{c}\text { Thick layer } \\
(81 \%)\end{array}$ & $\begin{array}{c}\text { Nail of the } \\
\text { little finger } \\
(60 \%)\end{array}$ & $\begin{array}{c}\text { A walnut of } \\
\text { product } \\
(74 \%)\end{array}$ & $\begin{array}{c}\text { A walnut of } \\
\text { product } \\
(94 \%) \\
\end{array}$ & $\begin{array}{c}\text { A walnut of } \\
\text { product } \\
(18 \%)\end{array}$ & $\begin{array}{c}\text { More than } \\
\text { a wet wipe } \\
(43 \%)\end{array}$ & $\begin{array}{l}\text { Thick } \\
\text { layer } \\
(39 \%)\end{array}$ & $\begin{array}{c}\text { Thick layer } \\
(51 \%)\end{array}$ \\
\hline $\begin{array}{c}\text { Site of } \\
\text { application }\end{array}$ & $\begin{array}{l}\text { Face } \\
(93 \%)\end{array}$ & $\begin{array}{l}\text { Teeth and } \\
\text { tongue } \\
(53 \%)\end{array}$ & $\begin{array}{l}\text { Wet skin } \\
(81 \%)\end{array}$ & $\begin{array}{l}\text { Wet scalp } \\
(92 \%)\end{array}$ & $\begin{array}{c}\text { Hair tips } \\
(22 \%)\end{array}$ & $\begin{array}{c}\text { Genital } \\
\text { area } \\
(43 \%)\end{array}$ & $\begin{array}{l}\text { Irritated } \\
\text { skin } \\
(40 \%)\end{array}$ & $\begin{array}{c}\text { All over the } \\
\text { body } \\
(66 \%)\end{array}$ \\
\hline
\end{tabular}

Note: * On sun exposure days.

Children usually take a daily bath (68.4\%) with application of a walnut of a bath gel (74.4\%) directly onto wet skin (81.2\%). Shampoo is also used on a daily basis by $40.8 \%$ of the children, while nearly a quarter (24.0\%) only uses it three times a week. Typically, a walnut-sized amount of the product $(93.6 \%)$ directly on the scalp $(91.6 \%)$. This frequency of utilization is consistent with a report of 0.7 times a day for bath products and shampoo [20]. Hair conditioner is not used by the majority of the population $(69.0 \%)$. When used, it is done once a day $(10.0 \%)$ applying a walnut of the product $(17.6 \%)$ at the hair tips $(21.6 \%)$.

The diaper change is made from one $(20.4 \%)$ to six $(15.2 \%)$ times a day, with an average of five times per day, which is higher than the reported three times a day in the already referenced study [20]. For the hygiene of the genital area, most parents use one $(23.2 \%)$ or more $(42.8 \%)$ baby wipes, while others use a cleansing product directly on wet skin $(31.6 \%)$. The diaper change barrier cream is applied as a thin $(28.8 \%)$ or thick layer $(38.8 \%)$, all over the genital area $(29.6 \%)$ or only on irritated skin patches $(40.0 \%)$.

Only a minority $(8.0 \%)$ of the analyzed children do not use sunscreen, but all of them are children under 12 months of age, which is in fact an age group where any sun exposure should be avoided. The vast majority of the parents said they do not apply sunscreen every day of the year (83.6\%), applying only in days of sun exposure, two $(22.0 \%)$, three $(26.4 \%)$ or four $(20.4 \%)$ times a day, with an average of 3 times per day. The product is usually applied all over the body $(65.6 \%)$ in a thin $(32.8 \%)$ or thick layer $(50.8 \%)$.

Based on the questionnaire results, 62 PCPs were selected as the most used by this population, and 17 other were added based on the sales statistics from two local hypermarkets (Table 2). These final 79 analyzed products were: twenty one moisturizers, seven toothpastes, thirteen bath gels, two soaps, one cleansing solution, nine shampoos, four hair conditioners, six baby wipes, eight diaper change creams, and eight sunscreens. 
Table 2. Selected personal care products (PCP) based on the level of use (\%) obtained in the questionnaires or from hypermarket statistics; respective galaxolide (HHCB) concentrations (highest concentrations in bold) and PCP presentation.

\begin{tabular}{|c|c|c|c|c|}
\hline PCP Type & PCP Code & $\begin{array}{c}\text { PCP Utilization } \\
(\%)\end{array}$ & $\begin{array}{c}\text { HHCB Concentration } \\
\left(\mathrm{mg} \cdot \mathrm{kg}^{-1} \text { Sample }\right)\end{array}$ & $\begin{array}{c}\text { PCP } \\
\text { Presentation }\end{array}$ \\
\hline \multirow{23}{*}{$\begin{array}{l}\text { Moisturizers } \\
\qquad(N=70)\end{array}$} & M1LC1 & 0.3 & $0.098 \pm 0.007$ & Lotion \\
\hline & $\mathrm{M} 2 \mathrm{CC} 1$ & 0.5 & $0.022 \pm 0.009$ & Cream \\
\hline & M3LC2 & 0.8 & $414.855 \pm 0.016$ & Lotion \\
\hline & $\mathrm{M} 4 \mathrm{CC} 2$ & 0.8 & $0.220 \pm 0.009$ & Cream \\
\hline & M5CR1 & 1.8 & $0.024 \pm 0.007$ & Cream \\
\hline & $\mathrm{M} 2 \mathrm{CC} 3$ & 1.8 & $0.169 \pm 0.010$ & Cream \\
\hline & $\mathrm{M} 6 \mathrm{CC} 4$ & 2.1 & $0.362 \pm 0.012$ & Cream \\
\hline & $\mathrm{M} 2 \mathrm{CC} 5$ & 2.6 & $0.018 \pm 0.011$ & Cream \\
\hline & M7LC3 & 3.2 & $0.032 \pm 0.009$ & Lotion \\
\hline & $\mathrm{M} 2 \mathrm{CR} 2$ & 3.9 & $0.034 \pm 0.007$ & Cream \\
\hline & M7LC4 & 4.7 & $0.406 \pm 0.010$ & Lotion \\
\hline & $\mathrm{M} 2 \mathrm{CC} 6$ & 4.7 & $0.058 \pm 0.007$ & Cream \\
\hline & $\mathrm{M} 8 \mathrm{CC} 7$ & 5.0 & nd & Cream \\
\hline & M5CC8 & 6.1 & $0.020 \pm 0.011$ & Cream \\
\hline & М9СС9 & 7.4 & $0.013 \pm 0.011$ & Cream \\
\hline & M4CR3 & 7.4 & $105.397 \pm 0.030$ & Cream \\
\hline & M4LC5 & 11.3 & $184.174 \pm 0.034$ & Lotion \\
\hline & M2LC6 & 15.0 & nd & Lotion \\
\hline & M5LC7 & $\mathrm{a}$ & $0.031 \pm 0.010$ & Lotion \\
\hline & M5LC8 & a & $0.023 \pm 0.011$ & Lotion \\
\hline & M7LC9 & a & $0.114 \pm 0.008$ & Lotion \\
\hline & Other PCPs $(n=49)$ & 20.5 & - & - \\
\hline & No answer; Don't Know/use & 1.1 & - & - \\
\hline \multirow{9}{*}{$\begin{array}{l}\text { Toothpastes } \\
\qquad(N=24)\end{array}$} & M10GD1 & 2.6 & nd & Gel \\
\hline & M10GD2 & 2.6 & $0.056 \pm 0.001$ & Gel \\
\hline & M11PD1 & 9.8 & $0.009 \pm 0.008$ & Paste \\
\hline & M12GD3 & 10.9 & nd & Gel \\
\hline & M13GD4 & 18.9 & $0.006 \pm 0.006$ & Gel \\
\hline & M14PD2 & 22.3 & $0.014 \pm 0.010$ & Paste \\
\hline & M15GD5 & a & nd & Gel \\
\hline & Other PCPs $(n=17)$ & 12.8 & - & - \\
\hline & No answer; Don’t Know/use & 20.1 & - & - \\
\hline
\end{tabular}


Table 2. Cont.

\begin{tabular}{|c|c|c|c|c|}
\hline РСР Туре & PCP Code & $\begin{array}{c}\text { PCP Utilization } \\
(\%) \\
\end{array}$ & $\begin{array}{c}\text { HHCB Concentration } \\
\left(\mathrm{mg} \cdot \mathrm{kg}^{-1} \text { Sample }\right)\end{array}$ & $\begin{array}{c}\text { PCP } \\
\text { Presentation } \\
\end{array}$ \\
\hline \multirow{18}{*}{$\begin{array}{l}\text { Body Bath Products } \\
\qquad(N=58)\end{array}$} & M16SB1 & 0.7 & $300.480 \pm 0.017$ & Soap \\
\hline & M17GB1 & 1.0 & $1.385 \pm 0.033$ & Gel \\
\hline & M18SB2 & 1.0 & $0.712 \pm 0.012$ & Soap \\
\hline & M7GB2 & 3.5 & $0.033 \pm 0.006$ & Gel \\
\hline & M4GB3 & 4.5 & $79.718 \pm 0.019$ & Gel \\
\hline & M9GB4 & 5.6 & $0.035 \pm 0.007$ & Gel \\
\hline & M2SL1 & 8.0 & $0.075 \pm 0.007$ & Solution \\
\hline & M4GB5 & 8.4 & $0.063 \pm 0.007$ & Gel \\
\hline & M5GB6 & 9.1 & $0.025 \pm 0.009$ & Gel \\
\hline & M7GB7 & 10.5 & $0.100 \pm 0.009$ & Gel \\
\hline & M2GB8 & 24.0 & $0.444 \pm 0.012$ & Gel \\
\hline & M1GB9 & a & $0.010 \pm 0.009$ & Gel \\
\hline & M1GB10 & a & $0.068 \pm 0.002$ & Gel \\
\hline & M5GB11 & a & $0.012 \pm 0.010$ & Gel \\
\hline & M7GB12 & a & $0.226 \pm 0.009$ & Gel \\
\hline & M3GB13 & a & $217.795 \pm 0.012$ & Gel \\
\hline & Other PCPs $(n=42)$ & 23.3 & - & - \\
\hline & No answer; Don’t Know/use & 0.3 & - & - \\
\hline \multirow{11}{*}{$\begin{array}{l}\text { Shampoos } \\
(N=25)\end{array}$} & M19CH1 & 1.7 & $0.038 \pm 0.007$ & Gel \\
\hline & M5CH2 & 10.4 & $0.193 \pm 0.010$ & Gel \\
\hline & $\mathrm{M} 4 \mathrm{CH} 3$ & 10.4 & $127.517 \pm \mathbf{0 . 0 3 0}$ & Gel \\
\hline & $\mathrm{M} 7 \mathrm{CH} 4$ & 52.2 & $0.005 \pm 0.005$ & Gel \\
\hline & M1CH5 & a & $0.035 \pm 0.006$ & Gel \\
\hline & M1CH6 & a & $0.796 \pm 0.019$ & Gel \\
\hline & M7CH7 & a & $0.089 \pm 0.008$ & Gel \\
\hline & M7CH8 & a & $0.346 \pm 0.010$ & Gel \\
\hline & M7CH9 & a & $0.209 \pm 0.010$ & Gel \\
\hline & Other PCPs $(n=16)$ & 0.9 & - & - \\
\hline & No answer; Don't Know/use & 24.3 & - & - \\
\hline \multirow{6}{*}{$\begin{array}{l}\text { Hair Conditioners } \\
\qquad(N=8)\end{array}$} & M20AS1 & 5.9 & $251.796 \pm 0.031$ & Solution \\
\hline & M7AC1 & 64.7 & $0.037 \pm 0.006$ & Cream \\
\hline & M7AC2 & a & $0.017 \pm 0.011$ & Cream \\
\hline & M7AS2 & a & $0.006 \pm 0.006$ & Solution \\
\hline & Other PCPs $(n=4)$ & 23.5 & - & - \\
\hline & No answer; Don't Know/use & 5.9 & - & - \\
\hline \multirow{8}{*}{$\begin{array}{l}\text { Baby Wipes } \\
\qquad(N=26)\end{array}$} & M17TL1 & 0.7 & $2.675 \pm 0.009$ & Wet wipe \\
\hline & M7TL2 & 3.0 & nd & Wet wipe \\
\hline & M4TL3 & 3.3 & nd & Wet wipe \\
\hline & M8TL4 & 4.6 & $0.001 \pm 0.001$ & Wet wipe \\
\hline & M21TL5 & 6.3 & $0.022 \pm 0.011$ & Wet wipe \\
\hline & M22TL6 & 43.4 & $0.154 \pm 0.010$ & Wet wipe \\
\hline & Other PCPs $(n=20)$ & 17.4 & - & - \\
\hline & No answer; Don't Know/use & 21.4 & - & - \\
\hline
\end{tabular}


Table 2. Cont.

\begin{tabular}{|c|c|c|c|c|}
\hline РСР Туре & PCP Code & $\begin{array}{c}\text { PCP Utilization } \\
(\%) \\
\end{array}$ & $\begin{array}{c}\text { HHCB Concentration } \\
\left(\mathrm{mg} \cdot \mathrm{kg}^{-1} \text { Sample }\right)\end{array}$ & $\begin{array}{c}\text { PCP } \\
\text { Presentation } \\
\end{array}$ \\
\hline \multirow{10}{*}{$\begin{array}{l}\text { Diaper Change } \\
\text { Products } \\
(N=28)\end{array}$} & $\mathrm{M} 2 \mathrm{CF} 1$ & 1.1 & $\begin{array}{ll}\text { nd } \\
\end{array}$ & Cream \\
\hline & M23CF2 & 1.4 & $0.012 \pm 0.011$ & Cream \\
\hline & M5CF3 & 3.2 & $0.207 \pm 0.008$ & Cream \\
\hline & M24PO1 & 4.9 & $1.234 \pm 0.025$ & Ointment \\
\hline & M2PA1 & 5.6 & $0.016 \pm 0.011$ & Paste \\
\hline & M4CF4 & 6.0 & $71.513 \pm 0.010$ & Cream \\
\hline & M6PA2 & 15.1 & $0.016 \pm 0.011$ & Paste \\
\hline & M23PO2 & 21.1 & nd & Ointment \\
\hline & Other PCPs $(n=20)$ & 18.3 & - & - \\
\hline & No answer; Don't Know/use & 23.2 & - & - \\
\hline \multirow{10}{*}{$\begin{array}{l}\text { Sunscreens } \\
\qquad(N=31)\end{array}$} & M25PL1 & 5.2 & $0.074 \pm 0.006$ & Lotion \\
\hline & M4CM1 & 6.6 & $1.005 \pm 0.023$ & Paste \\
\hline & M26PL2 & 9.0 & $12.312 \pm 0.010$ & Lotion \\
\hline & M2PL3 & 9.4 & $0.051 \pm 0.007$ & Lotion \\
\hline & M2CM1 & 11.5 & $0.344 \pm 0.010$ & Paste \\
\hline & M27PL4 & 12.8 & $0.229 \pm 0.010$ & Lotion \\
\hline & M27CM2 & 15.3 & $0.394 \pm 0.011$ & Paste \\
\hline & M1PL5 & a & $134.715 \pm 0.025$ & Lotion \\
\hline & Other PCPs $(n=23)$ & 21.9 & - & - \\
\hline & No answer; Don't Know/use & 8.3 & - & - \\
\hline
\end{tabular}

Notes: ${ }^{\text {a }}$ Indicated by hypermarkets statistics; ${ }^{\text {nd }}$ not detectable.

\subsection{HHCB Concentrations}

The final results for the analyzed PCPs are presented in Table 2. Product brands and designations were encoded as a PCP code representing the number of the mark (M\#) followed by a product number according to the presentation and use of that product. For example, brand 1 has a body lotion (M1LC1), two bath gels (M1GB9, M1GB10), two shampoos (M1CH5, M1CH6) and a sunscreen lotion (M1PL5).

HHCB was detected in 70 of the 79 analyzed PCPs, within a wide range of concentrations that were consistent with other studies, although all of them respective PCPs for adults [3,13-17]. The HHCB concentrations ranged from $0.001 \pm 0.001 \mathrm{mg} \cdot \mathrm{kg}^{-1}$, on a baby wipe (M8TL4) to $300.480 \pm 8.819 \mathrm{mg} \cdot \mathrm{kg}^{-1}$, on glycerin soap (M16SB1). The highest HHCB concentrations were found in ten products (bold PCP codes in Table 2), and five of them are from brand M4 (with nine analyzed products). The nine products with concentrations of HHCB below the limit of detection $\left(\mathrm{LOD}=0.001 \mathrm{mg} \cdot \mathrm{kg}^{-1}\right.$ sample) are indicated as not detectable (nd) in Table 2 and two of them are from brand M2 (with twelve analyzed products). In this study, 29 of the analyzed PCPs were labeled as "fragrance-free", but only six of them have actually a non-detectable amount of HHCB. Among these "fragrance-free" products, the detectable HHCB concentrations varied between $0.001 \pm 0.001$ and $71.513 \pm 0.010 \mathrm{mg} \cdot \mathrm{kg}^{-1}$, and therefore, most of them cannot be considered as residual quantities. On the other hand, three of the 50 PCPs that include "parfum" or "fragrance" in their compositions, were 
found to have no detectable $\mathrm{HHCB}$, indicating that those products may contain other fragrance ingredients, rather than HHCB.

All presented concentrations were corrected by their respective recovery (Table 3), determined as described before [15], and ranging from $65 \%$ in lotion moisturizers and sunscreens (with a $320.0 \mathrm{mg} \cdot \mathrm{kg}^{-1}$ sample spike) and $98 \%$ in soaps (with a $227.5 \mathrm{mg} \cdot \mathrm{kg}^{-1}$ sample spike) and creams (with a $300.0 \mathrm{mg} \cdot \mathrm{kg}^{-1}$ sample spike).

Table 3. Selected personal care products (PCP) for the recovery assays of each PCP category, respective galaxolide (HHCB) concentrations, HHCB spikes, and recoveries (\%).

\begin{tabular}{cccccc}
\hline PCP Category & $\begin{array}{c}\text { PCP } \\
\text { Presentation }\end{array}$ & PCP Code & $\begin{array}{c}\text { HHCB } \\
\text { Concentration } \\
(\mathbf{m g} \cdot \mathbf{k g} \mathbf{- 1} \text { Sample) }\end{array}$ & $\begin{array}{c}\text { HHCB } \\
\text { Concentration Spike } \\
\left(\mathbf{m g} \cdot \mathbf{k g}^{-\mathbf{1}} \mathbf{S a m p l e}\right)\end{array}$ & $\begin{array}{c}\text { HHCB } \\
\text { Recovery } \\
\mathbf{( \% )}\end{array}$ \\
\hline \multirow{2}{*}{ Moisturizers } & Lotion & M7LC3 & $0.032 \pm 0.009$ & 320.0 & 65 \\
& Cream & M4CR3 & $105.397 \pm 0.030$ & 300.0 & 98 \\
\hline \multirow{2}{*}{ Toothpastes } & Paste & M14PD2 & $0.014 \pm 0.010$ & 300.0 & 80 \\
& Gel & M15GD5 & nd & 227.5 & 80 \\
\hline \multirow{2}{*}{ Body Bath } & Soap & M16SB1 & $300.480 \pm 0.017$ & 227.5 & 98 \\
Products & Solution & M2SL1 & $0.075 \pm 0.007$ & 230.0 & 85 \\
& Gel & M1GB9 & $0.010 \pm 0.009$ & 230.0 & 84 \\
\hline Shampoos & Gel & M4CH3 & $127.517 \pm 0.030$ & 300.0 & 81 \\
Hair & Cream & M7AC2 & $0.017 \pm 0.011$ & 227.5 & 75 \\
\hline Baby Witioners & Wet wipe & M17TL1 & $2.675 \pm 0.009$ & 227.5 & 68 \\
\hline Diaper Change & Paste & M27CM2 & $0.394 \pm 0.011$ & 230.0 & 79 \\
Products & Ointment & M24PO1 & $1.234 \pm 0.025$ & 320.0 & 70 \\
\hline \multirow{2}{*}{ Sunscreens } & Lotion & M7LC3 & $0.032 \pm 0.009$ & 320.0 & 65 \\
\hline
\end{tabular}

Note: ${ }^{\text {nd }}$ not detectable.

\subsection{HHCB Risk of Dermal Exposure}

Considering children's consumer habits previously obtained by the referenced questionnaire, an estimation of the total daily dermal exposure to HHCB of this population was performed (Table 4). The mean daily application amount was estimated based on the responses obtained from the questionnaire annex (Supplementary File-Questionnaire). Average retention factors on skin for each type of PCP were based on values reported in scientific literature [21] for similar products: 100\% for leave-on products (body lotions, creams, wet wipes, and sunscreens) and 10\% for rinse-off products (toothpastes, bath gels, soap bars, shampoos, and hair conditioners). The mean daily HHCB retention for each type of PCP was calculated as the product of mean HHCB concentrations on each group (considering measured concentrations in Table 2), mean daily applied amount, and the respective retention factor. Total daily dermal exposure risk was obtained by the sum of all HHCB retained from daily use of PCPs. 
Table 4. Estimated mean daily dermal exposure to $\operatorname{HHCB}\left(\mu \mathrm{g} \cdot \mathrm{day}^{-1}\right)$ using the analyzed PCPs.

\begin{tabular}{|c|c|c|c|c|c|c|c|}
\hline $\begin{array}{c}\text { Personal Care } \\
\text { Products } \\
\text { (PCPs) }\end{array}$ & $\begin{array}{c}\text { Application } \\
\text { Site }\end{array}$ & $\begin{array}{c}\text { Exposure } \\
\text { Route }\end{array}$ & $\begin{array}{l}\text { Number of } \\
\text { Analyzed } \\
\text { PCPs }\end{array}$ & $\begin{array}{c}\text { Mean HHCB } \\
\text { Concentration }{ }^{\mathrm{c}} \\
\left(\mathrm{mg} \cdot \mathrm{kg}^{-1} \text { Sample) }\right.\end{array}$ & $\begin{array}{c}\text { Mean daily } \\
\text { Application } \\
\text { Amount } \\
\left(\mathrm{g} \cdot \text { Sample } \cdot \text { day }^{-1}\right)\end{array}$ & $\begin{array}{c}\text { Retention } \\
\text { Factor (\%) } \\
\text { [21] }\end{array}$ & $\begin{array}{c}\text { Mean Daily } \\
\text { HHCB } \\
\text { Retention } \\
\left(\mu \mathrm{g} \cdot \mathrm{day}^{-1}\right) \\
\end{array}$ \\
\hline $\begin{array}{l}\text { Body lotions/ } \\
\text { creams }\end{array}$ & Whole body & Dermal & 18 & 37.539 & 1.4 & $100.0 \%$ & 52.5541 \\
\hline Facial creams & Face & Dermal & 3 & 35.152 & 0.5 & $100.0 \%$ & 17.5759 \\
\hline Toothpastes & $\begin{array}{l}\text { Perioral region } \\
\text { and mouth } \\
\text { mucous } \\
\text { membranes }\end{array}$ & $\begin{array}{l}\text { Dermal } \\
\text { and oral }\end{array}$ & 7 & 0.021 & 0.2 & $10.0 \%$ & 0.0004 \\
\hline Bath gels & Whole body & Dermal & 14 & 21.428 & 2.1 & $10.0 \%$ & 4.4998 \\
\hline Soap bars & Hands & Dermal & 2 & 150.431 & 1.1 & $10.0 \%$ & 16.5474 \\
\hline Shampoos & $\begin{array}{l}\text { Scalp, neck } \\
\text { and hands }\end{array}$ & Dermal & 9 & 14.359 & 0.9 & $10.0 \%$ & 1.2923 \\
\hline $\begin{array}{c}\text { Hair } \\
\text { conditioners }\end{array}$ & $\begin{array}{c}\text { Hair tips and } \\
\text { hands }\end{array}$ & Dermal & 4 & 62.964 & 0.6 & $10.0 \%$ & 3.7779 \\
\hline Baby wipes ${ }^{a}$ & Genital area & Dermal & 6 & 0.713 & 21.7 & $100.0 \%$ & 9.9853 \\
\hline $\begin{array}{l}\text { Diaper change } \\
\text { creams }\end{array}$ & Genital area & Dermal & 8 & 12.167 & 0.7 & $100.0 \%$ & 8.5166 \\
\hline Sunscreens ${ }^{b}$ & Whole body & Dermal & 8 & 18.672 & 8.4 & $100.0 \%$ & 156.8443 \\
\hline \multicolumn{7}{|c|}{ Total daily dermal exposure to $\mathrm{HHCB}\left(\mu \mathrm{g} \cdot\right.$ day $\left.^{-1}\right)$} & $277.10 \pm 0.02$ \\
\hline
\end{tabular}

Notes: ${ }^{a}$ mean daily application calculated based on the questionnaire annex answers that indicate an average of 7 baby wipes a day and about $3.1 \mathrm{~g}$ each wipe; ${ }^{\mathrm{b}}$ mean daily application calculated assuming a sun exposure day (3 times a day in thick layer, Table 1); because no answers were obtained for the annex to the questionnaire related to sunscreens, the application of a thick layer was assumed to be twice the amount of body lotions/creams (thin layer); ${ }^{c}$ Mean HHCB concentrations for all the analysed PCPs in each category of products (Table 2 ).

The lowest mean HHCB concentrations (Table 4) were found in toothpastes and baby wipes, while the highest mean concentration corresponded to soap bars. Soap bars can irritate the skin due to its alkaline $\mathrm{pH}$ and due to the presence of some additives, like fragrances [11], which can raise the risk of exposure to HHCB. Nevertheless, these kind of PCPs were not the most relevant ones to the estimated total daily dermal exposure risk, as soap bars were only considered to be used for washing hands, and, therefore, used on a reduced exposure area. In cases where they are used for body wash, their influence to dermal exposure may be higher. The highest contribution for the estimated dermal exposure risk, then, was found to be from leave-on-products applied onto the whole body (Table 4): sunscreens, assuming a sun exposure day, and body lotions/creams, on the other days. Additionally, it is expected that penetration is greater for longer contact times and surface areas [22]. Consequently, leave-on-products applied onto the whole body, like moisturizers and sunscreens, should be the most absorbed ones. It is also reported that the penetration varies with the application site of the PCP, of which the most critical ones are the genitals, head and trunk [23], so only this last site could more greatly affect the dermal exposure risk from moisturizers and sunscreens. Toothpastes were the PCPs 
that contributed less to the total dermal exposure risk, which is consistent with the small area of the oral cavity, small applied quantities, short contact time, and low detected HHCB concentrations found in these kind of products (some not detectable). Nevertheless, it should be noted that there is still some risk of oral exposure from toothpastes, although this is not a major route.

The estimated total daily dermal exposure to HHCB was $277.10 \pm 0.02 \mu \mathrm{g} \cdot \mathrm{day}^{-1}$ (Table 4) considering the mean application amount for each kind of PCP used by all the children's age groups. Observing data in detail and the differences between the youngest and the oldest children consumer habits, we can notice that the total daily dermal exposure risk is about $132.38 \pm 0.01 \mu \mathrm{g} \cdot \mathrm{day}^{-1}$ for children less than 1 year old and $169.16 \pm 0.02 \mu \mathrm{g} \cdot \mathrm{day}^{-1}$ for children older than 4 years. The lower levels for these two age groups, at the lower and upper end of the studied population, are justified by the fact that the youngest ones do not yet use sunscreens $(46.5 \%)$ or toothpastes $(81.4 \%)$, while the oldest ones use no more diaper change products (53.7\%). The middle-aged groups have a higher mean daily dermal exposure risk to HHCB $\left(297.98 \pm 0.02 \mu \mathrm{g} \cdot\right.$ day $\left.^{-1}\right)$ because they already use sunscreens and still use considerable amounts of diaper change products. All of the estimated daily dermal exposure risks are below other published results for adults $\left(904 \mu \mathrm{g} \cdot \mathrm{day}^{-1}\right.$ [15] (3060 $\mu \mathrm{g} \cdot \mathrm{day}^{-1}$ [14], $25,100 \mu \mathrm{g} \cdot \mathrm{day}^{-1}[3]$ and $23,700 \mu \mathrm{g} \cdot \mathrm{day}^{-1}$ [13]), which is consistent with the fact that children's PCPs are expected to be less fragranced than adult's ones and the used amounts are also smaller in children. Although rather small amounts are predicted to be retained by children's skin, exposure risk can be higher than in adults, especially when the epidermal barrier is compromised due to some common children's skin disorders. To the authors' best knowledge, no studies were found about children's dermal exposure to $\mathrm{HHCB}$, but a study in the elderly population, with an altered epidermal barrier, showed a higher systemic absorption of musks than in healthy adults [12]. A common children's skin disorder that may alter epidermal barrier is atopic skin, but it should be mentioned that the six analysed body creams for this kind of skin have a mean HHCB concentration value of $0.134 \mathrm{mg} \cdot \mathrm{kg}^{-1} \mathrm{sample}$, which is a low contribution for dermal exposure to HHCB in children.

Considering the estimated total daily dermal exposure risk to HHCB and a total evaporation factor of $22 \%$ [24], only $216 \mu \mathrm{g} \cdot \mathrm{day}^{-1}$ remains on the skin surface and may be absorbed. There is limited information about HHCB dermal absorption, but the human skin absorption has been reported as $19.5 \%$, of which only $0.1 \%$ eventually enters the systemic circulation [24]. However, different rates are expected when dealing with children or baby skin [7-9]. Considering the same level of absorption for all PCPs for children and adults, and assuming an average body weight (BW) of $17.2 \mathrm{~kg}$ for a 4-year-old child [25], dermal exposure will be about $0.02 \mu \mathrm{g} \cdot \mathrm{kg} \cdot \mathrm{BW}^{-1} \cdot \mathrm{day}^{-1}$. To the author's best knowledge, no other values of dermal exposure of children to HHCB due to PCP use was reported. Only one study was found where dermal exposure of children to toys scented with several fragrances was evaluated and reported values were significantly higher, ranging from 8.6 to $605.0 \mu \mathrm{g} \cdot \mathrm{kg} \cdot \mathrm{BW}^{-1} \cdot \mathrm{day}^{-1}$ [25].

\section{Conclusions}

PCP consumption habits of children population from the Oporto district was established by a questionnaire applied to 250 children. The frequency and mode of application of the PCPs, estimated by the results of this survey, permitted to establish the common applied quantities. Additionally, HHCB was detected in 70 of the 79 most used PCPs in concentrations ranging 
from $0.001 \pm 0.001 \mathrm{mg} \cdot \mathrm{kg}^{-1}$, found on a baby wipe, and $300.480 \pm 8.819 \mathrm{mg} \cdot \mathrm{kg}^{-1}$, detected in glycerin soap. The frequency and mode of application of the PCPs, estimated by the results of this survey, permit researchers to establish the common applied quantities. With these results, it was possible to determine the children's dermal exposure to HHCB from personal care products in Oporto as $277.10 \pm 0.02 \mu \mathrm{g} \cdot \mathrm{day}^{-1}$.

\section{Acknowledgments}

This work has been partially funded by funds through the Operational Programme for Competitiveness Factors (COMPETE), O Novo Norte-North Portugal Regional Operational Programme (ON.2), by National Funds through FCT (under the projects PEst-C/EQB/UI0511, NORTE-07-0124-FEDER000025-RL2_Environment\&Health) and by Instituto Politécnico do Porto (IPP). Patrícia Correia would like to thank Foundation for Science and Technology (FCT, Portugal) for the doctoral grant SFRH/BD/70945/2010, co-funded by the Quadro de Referência Estratégico Nacional-Programa Operacional de Potencial Humano (QREN-POPH).

\section{Author Contributions}

Arminda Alves, Lúcia Santos and Agostinho Cruz conceived and designed the experiments. Patrícia Correia performed the experiments and analyzed the data. All the authors wrote the paper.

\section{Conflicts of Interest}

The authors declare no conflict of interest.

\section{References}

1. Arbulu, M.; Sampedro, M.C.; Unceta, N.; Gómez-Caballero, A.; Goicolea, M.A.; Barrio, R.J. A retention time locked gas chromatography-mass spectrometry method based on stir-bar sorptive extraction and thermal desorption for automated determination of synthetic musk fragrances in natural and wastewaters. J. Chromatogr. A 2011, 1218, 3048-3055.

2. HERA (Human and Environmental Risk Assessment on Ingredients of Household Cleaning Products), Environmental Risk Assessment Polycyclic Musks AHTN (CAS 1506-02-1) and HHCB (CAS 122-05-05), 2004. Available online: http://www.heraproject.com/RiskAssessment.cfm? subID $=29$ (accessed on 2 September 2011).

3. Reiner, J.L.; Kannan, K. A survey of polycyclic musks in selected household commodities from the United States. Chemosphere 2006, 62, 867-873.

4. Bagasra, O.; Golkar, Z.; Garcia, M.; Rice, L.N.; Pace, D.G. Role of perfumes in pathogenesis of autism. Med. Hypoth. 2013, 80, 795-803.

5. Regulation of the European Parliament and of the Council on Cosmetic Products (recast); PE-CONS 3623/09, 2009. Available online: http://register.consilium.europa.eu/doc/srv?l=EN\&f=ST\% 203623\%202009\%20INIT (accessed on 25 August 2011).

6. Bridges, B. Fragrance: Emerging health and environmental concerns. Flavour Fragr. J. 2002, 17, 361-371. 
7. Fluhr, J.; Darlenski, R.; Taieb, A.; Hachem, J.-P.; Baudouin, C.; Msika, P.; de Belilovsky, C.; Berardesca, E. Functional skin adaptation in infancy-Almost complete but not fully competent. Exp. Dermatol. 2010, 19, 483-492.

8. Blume-Peytavi, U.; Hauser, M.; Stamatas, G.N.; Pathirana, D.; Bartels, N.G. Skin care practices for newborns and infants: Review of the clinical evidence for best practices. Pediatr. Dermatol. 2012, 29, 1-14.

9. Lavender, T.; Bedwell, C.; O’Brien, E.; Cork, M.J.; Turner, M.; Hart, A. Infant skin-cleansing product versus water: A pilot randomized, assessor-blinded controlled trial. BMC Pediatr. 2011, 11, doi:10.1186/1471-2431-11-35.

10. Stamatas, G.N.; Nikolovski, J.; Mack, M.C.; Kollias, N. Infant skin physiology and development during the first years of life: A review of recent findings based on in vivo studies. Int. J. Cosmet. Sci. 2011, 33, 17-24.

11. Imai, S.; Kuwabara, C. Infant skin and its care. Cosmet. Toilet. 1992, 107, 85-90.

12. Hutter, H.P.; Wallner, P.; Hartl, W.; Uhl, M.; Lorbeer, G.; Gminski, R.; Mersh-Sundermann, V.; Kundi, M. Higher blood concentrations of synthetic musks in women above fifty years than in younger women. Int. J. Hyg. Environ. Health 2010, 213, 124-130.

13. Roosens, L.; Covaci, A.; Neels, H. Concentrations of synthetic musk compounds in personal care and sanitation products and human exposure profiles through dermal application. Chemosphere 2007, 69, 1540-1547.

14. Lu, Y.; Yuan, T.; Wang, W.; Kannan, K. Concentrations and assessment of exposure to siloxanes and synthetic musks in personal care products from China. Environ. Pollut. 2011, 159, 3522-3528.

15. Correia, P.; Cruz, A.; Santos, L.; Alves, A. Human dermal exposure to galaxolide from personal care products. Int. J. Cosmet. Sci. 2013, 35, 299-309.

16. Zhang, X.; Yao, Y.; Zeng, X.; Qian, G.; Guo, Y.; Wu, M.; Sheng, G.; Fu, J. Synthetic musks in the aquatic environment and personal care products in Shanghai, China. Chemosphere 2008, 72, 1553-1558.

17. Martínez-Girón, A.B.; Crego, A.L.; González, M.J.; Marina, M.L. Enantiomeric separation of chiral polycyclic musks by capillary electrophoresis: Application to the analysis of cosmetic samples. J. Chromatogr. A 2010, 1217, 1157-1165.

18. Schüssler,W.; Nitschke, L. Determination of trace amounts of Galaxolide ${ }^{\circledR}$ (HHCB) by HPLC. Fresenius J. Anal. Chem. 1998, 361, 220-221.

19. Instituto Nacional de Estatística (Statistics Portugal), INE, IP, Censos 2011-XV Recenseamento geral da população, V Recenseamento geral da habitação-Resultados provisórios , Lisboa, Portugal, 2011. Available online: $h t t p: / w w w . g o o g l e . p t / u r l ? s a=t \& r c t=j \& q=\& e s r c=s \&$ source=web\&cd=1\&ved= 0CB8QFjAA\&url=http\%3A\%2F\%2Fcensos.ine.pt\%2Fngt_server\%2Fattachfileu.jsp\%3Flook_pare ntBoui\%3D131010986\%26att_display\%3Dn\%26att_download\%3Dy\&ei=Q1QwVeyvMKiR7Aat 7oDgDg\&usg=AFQjCNEdobEaXIfk1EIB_1v7sI117bsbrA (accessed on 20 November 2014). (In Portuguese)

20. Bonamonte, D.; Filoni, A.; Vestita, M.; Angelini, G.; Foti, C. Market trends in baby skin care products and implications for clinical practice. Pediatr. Dermatol. 2014, 31, 734-738.

21. Cadby, P.A.; Troy, W.R.; Vey, M.G.H. Consumer exposure to fragrance ingredients: Providing estimates for safety evaluation. Regul. Toxicol. Pharmacol. 2002, 36, 246-252. 
22. Wester, R.C.; Maibach, H.I. Interrelationships in the dose-response of percutaneous absorption. In Topical Absorption of Dermatological Products; Bronaugh, R.L., Maibach, H.I., Eds.; Marcel Dekker, Inc.: New York, NY, USA, 2002; pp. 169-184.

23. Wester, R.C.; Maibach, H.I. Regional variation in percutaneous absortion. In Topical Absorption of Dermatological Products; Bronaugh, R.L., Maibach, H.I., Eds.; Marcel Dekker, Inc.: New York, NY, USA, 2002; pp. 33-39.

24. Ford, R.A.; Hawkins, D.R.; Schwarzenbach, R.; Api, A.M. The systemic exposure to the polycyclic musks, AHTN and HHCB, under conditions of use as fragrance ingredients: Evidence of lack of complete absorption from a skin reservoir. Toxicol. Lett. 1999, 111, 133-142.

25. Masuck, I.; Hutzler, C.; Luch, A. Estimation of dermal and oral exposure of children to scented toys: Analysis of the migration of fragrance allergens by dynamic headspace GC-MS. J. Sep. Sci. 2011, 34, 2686-2696.

(C) 2015 by the authors; licensee MDPI, Basel, Switzerland. This article is an open access article distributed under the terms and conditions of the Creative Commons Attribution license (http://creativecommons.org/licenses/by/4.0/). 